Original Research Paper

\title{
On the Design and Construction of a Dual Axis Solar Tracker Prototype for a Dish Concentrator using ATMega3298P Microcontroller
}

\author{
${ }^{1}$ Albright Abu Edet, ${ }^{2}$ Samaila Umaru and ${ }^{3}$ Isah Ibrahim \\ ${ }^{1}$ Department of Mechanical Engineering, Ahmadu Bello University, Zaria, Nigeria \\ ${ }^{2}$ Air Force Institute of Technology, Kaduna, Nigeria \\ ${ }^{3}$ Department of Mechanical Engineering, Ahmadu Bello University, Zaria, Nigeria
}

\section{Article history}

Received: 04-02-2021

Revised: 23-03-2021

Accepted: 28-03-2021

Corresponding Author: Albright Abu Edet

Department of Mechanical Engineering, Ahmadu Bello University, Zaria, Nigeria Email: albrightedet@gmail.com

\begin{abstract}
The desire for reliable power supply is the reason for further research into alternative sources of power. Although solar tracking is not a new technology, yet solar harvesters still suffer low efficiency due to the intermittence of solar insolation. Thus many smart systems have been designed to maximise solar harvesters. Among the systems is the dual axis solar tracking system. For demonstration of the tracking system, a prototype was developed as a model for a conventional tracking system. It met its objective of tracking solar irradiance and accordingly re-orient the payload in real time to the point of maximum solar insolation. Testing and observation using the developed prototype gave evidence to the fact that solar trackers can increase the efficiency of solar harvesters. The results showed steady solar tracking for $6 \mathrm{~h}$ starting from 9:00 am-3:15 pm. The sensitivity of the sensors allow the system to track solar insolation as low as $>5$ lumen. The entire system was powered by 5 volts which made it energy efficient and can be run at low cost.
\end{abstract}

Keywords: ATMega328P, AVR, Micro-Controller, Arduino, Prototype, Solar, Tracking System, Dish Concentrator, C Programming Language, Systems, Mechatronic

\section{Introduction}

Solar energy is a clean source of energy that is free from environmental pollution. It is one of the alternative energy sources that has vast potential. Harnessing this energy follows different methods depending on the need, whether for electricity or heating using solar collectors. Many projects have been designed and constructed to utilize solar energy and all have pointed to the importance of solar trackers in order to increase the efficiency of the system. A solar tracker is a mechatronic system designed to follow the movement of the sun. There are basically two types of solar trackers namely; A Single axis solar tracker and a Dual axis solar tracker (Hafez et al., 2018). The single axis solar tracker is one that is fixed at an angle equal to the latitude of the location where it is installed and is capable of following the sun on one axis only from East to West throughout the day by way of a rotating mechanism. While the dual axis solar tracker is another setup quite similar to that of the single-axis tracker. The only difference is that an extra degree of freedom is added to the system, in that the tracker can rotate on a dual axis, that is "East to West" and "North to South." Orientation (Lee and Rahim, 2013).

\section{Description of the Developed Solar Tracker}

The prototype developed was cut out from perspex as shown in Fig. 1. Perspex was used due to ease of fabrication. The lower arm being the primary axis module moves from North-South $\left(0-180^{\circ}\right)$ with the help of a servo motor, while the upper arm being the secondary module moves from East-West $\left(0-180^{\circ}\right)$ by a servo motor. A combination of both movement results in a dual axis movement. The payload being the dish concentrator was cut out of plastic plate and covered with a reflector. A sensor pyramid like that of (Mareeswari et al., 2019) as shown in Fig. 2 was also designed using four Light dependent resistors, all separated with a cross bar which was designed to cast a shadow on the sensors and thus vary the luminous intensity of the sun on the sensors. 


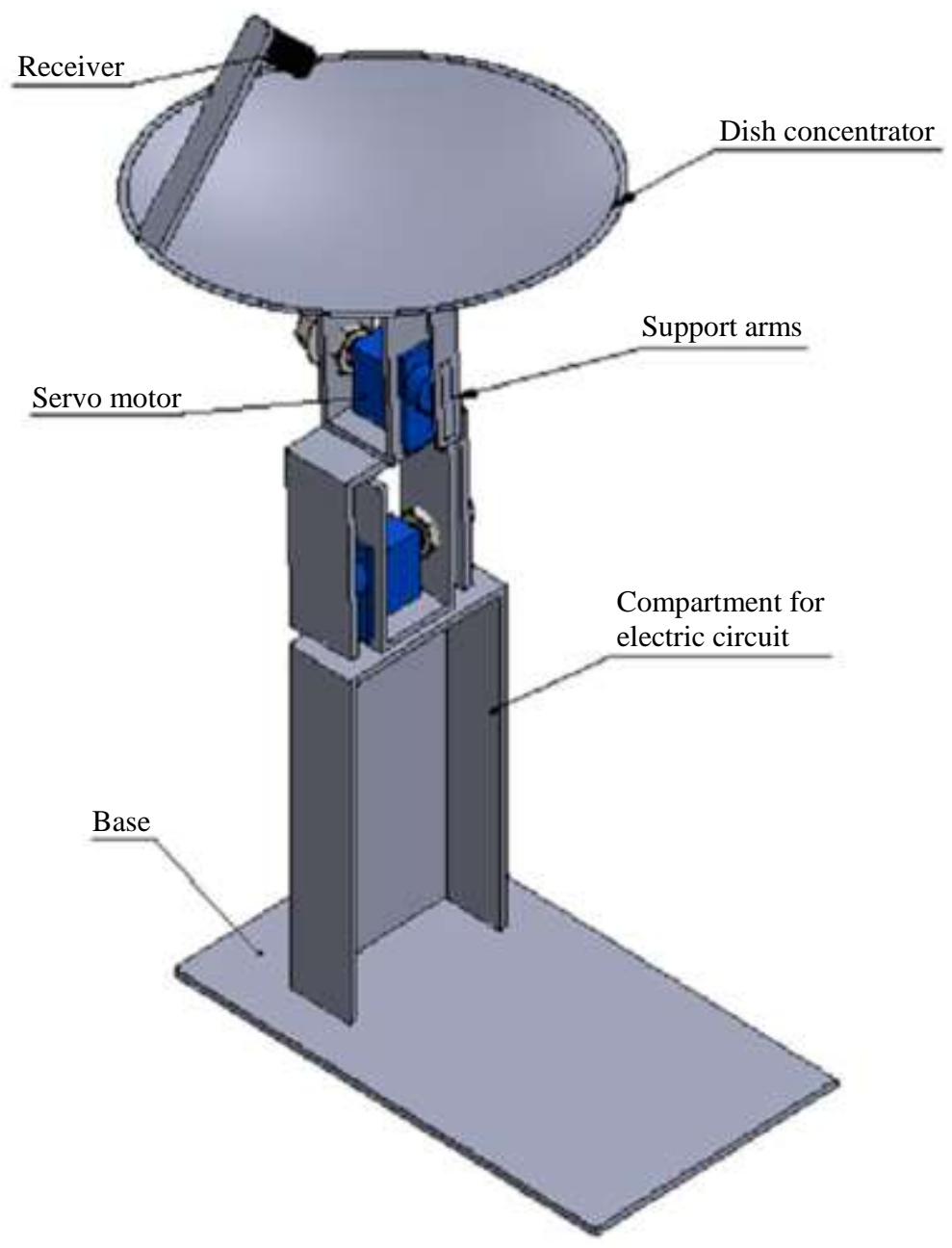

Fig. 1: A picture of the prototype

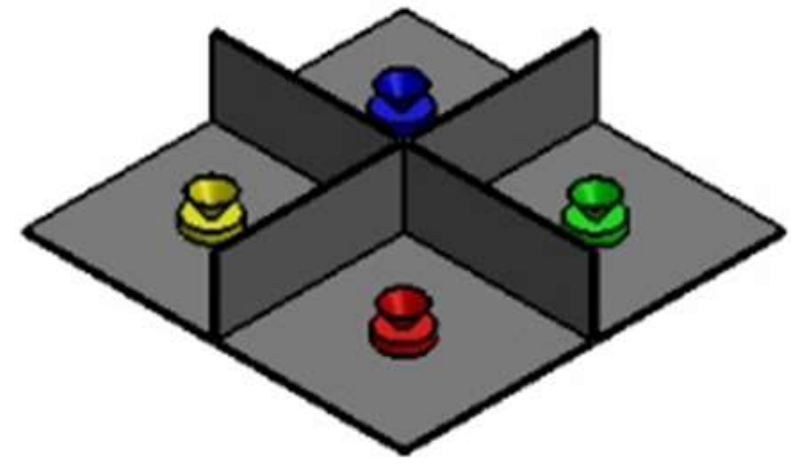

Fig. 2: Sensor pyramid showing four sensors each representing (North, South, East and West)

\section{Working Principle of the Tracker}

The solar tracker was designed such that at sunrise the sensors (LDR) will receive the light reflected by the rising sun and then send electronic pulses to the micro-controller which in-turn drives the servo motors to actualize a position of facing the sun. From then on the tracking system will follow the sun as it crosses from the east to the west which is about $0-180^{\circ}$ from the eastern horizon to the western horizon. As the tracker moves with the sun, it will align the concentrator to face the sun rays directly, thus receiving a huge amount of sunlight for a longer period of time. With the load in position, achieving a correct position of the concentrator is very important in the entire design and at night when there is no sun, the tracker is programed to return to $0^{\circ}$ (facing East) position which is its position at sunrise in order to give the sensors a horizontal view of the rising sun.

\section{Materials}

The materials used for the project were:

1. $10,000 \Omega$ Resistors 
2. Vero board/bread board

3. Electronic sensors (LDR: Light dependent resistors)

4. Micro controller: ATmega328P

5. $9 \mathrm{~g}$ Servo motors

6. Perspex

7. Jumper wires

\section{Methodology}

The following methods were adopted in the development of the prototype (Fig. 3):

1. Use of solid works Integrated development environment for computer aided design of the prototype

2. Design of the electronic circuit

3. Selection of materials for the prototype hardware

4. Fabrication of parts

5. Development of the electronic circuit

6. Development of the flow chart and code using $\mathrm{C}$ programming language

7. Interfacing Hardware and firmware components

8. Testing

\section{Testing Procedure}

The test was conducted for $15 \mathrm{~min}$ from (6:00-6:15 am), (9:00-9:15 am), (12:00-12:15 pm), (3:00-3:15 pm) and (6:00-6:15 pm).

For every one hour the sun would move by $15^{\circ}$ across the sky (Thomas and Stephen, 2014).

Therefore:

If $15^{\circ}=1 \mathrm{~h}$ (which is $60 \mathrm{~min}$ )

Then $3^{\circ}=15 \mathrm{~min}$

The tracker was programmed to track the sun automatically once the luminous intensity was greater than five lumen and the output displayed on the serial monitor at 3 min intervals. The tracker was placed facing the south with an azimuth of $11^{\circ}$.

\section{Flow Chart}

The tracker flow chart as in Fig. 4 shows the steps taken by the system to execute its function. Each step is executed line by line starting from the top where solar irradiance is received by the light dependent resistors and converted to electric signal and fed to the micro-controller which performs logical comparisons of the signal and then transmits to the actuators if the difference is logically true and if the difference is logically false, the process goes back again to the top and repeats the steps.

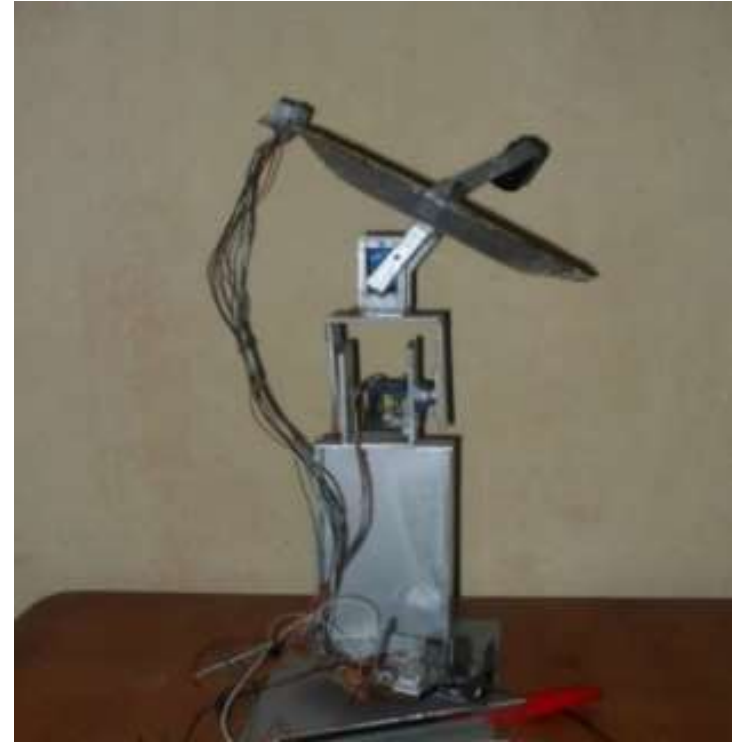

Fig. 3: The developed prototype

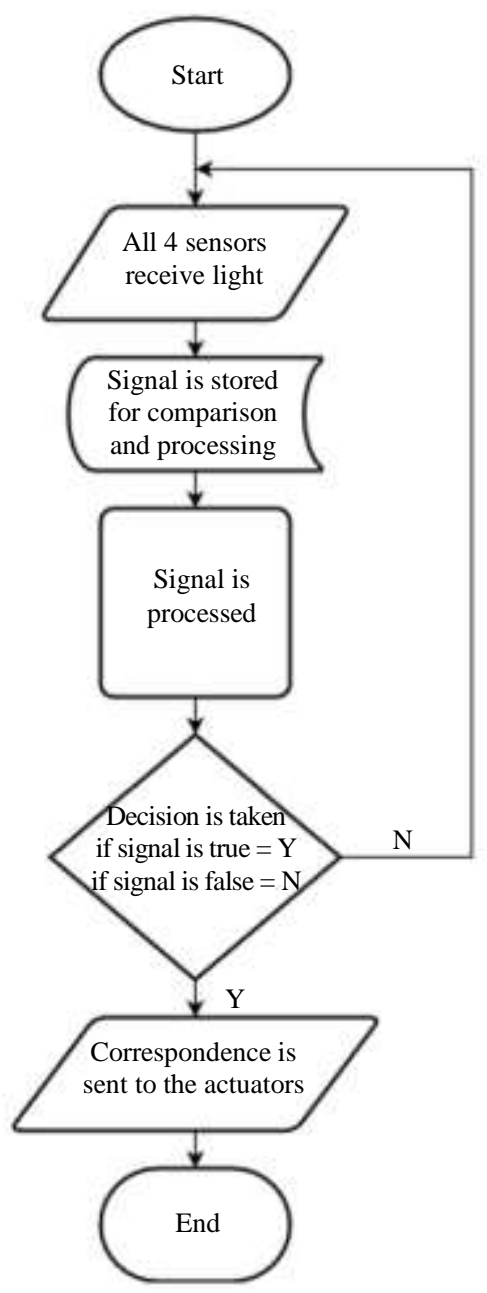

Fig. 4: Flow chart and code 


\section{Discussion}

From the results on Table 1, the LDR (North) received the highest solar irradiance because the sensor was facing the rising sun at a wider angle, more than the other 3 sensors. 9:00 am-3:12 pm shows a steady tracking of the sun at almost 1000 lumen. It also shows how much energy that can be harnessed from directly facing the payload to the sun as tracking continues. The high sensitivity of the sensors allows the system to start tracking luminous intensity early, as low as $>5$ lumen and later beyond 6:00 pm until the irradiance goes less than 5 lumen as in Fig. 5. When the irradiance is less than 5 lumen the system returns to home position to await the rising sun.

Table 1: Solar Irradiance over time from (6:00 am-6:15 pm) as captured by each sensor

\begin{tabular}{|c|c|c|c|c|}
\hline Time & LDR (North) & LDR (South) & LDR (East) & LDR (West) \\
\hline 6:00 AM & 8 & 9 & 10 & 6 \\
\hline 6:03 AM & 14 & 22 & 23 & 11 \\
\hline 6:06 AM & 37 & 40 & 43 & 27 \\
\hline 6:09 AM & 72 & 69 & 67 & 55 \\
\hline $6: 12$ AM & 123 & 116 & 103 & 100 \\
\hline 6:15 AM & 191 & 192 & 163 & 163 \\
\hline 9:00 AM & 933 & 964 & 979 & 925 \\
\hline 9:03 AM & 937 & 977 & 981 & 930 \\
\hline 9:06 AM & 950 & 990 & 983 & 939 \\
\hline 9:09 AM & 967 & 992 & 984 & 948 \\
\hline 9:12 AM & 979 & 989 & 984 & 957 \\
\hline $9: 15$ AM & 982 & 992 & 985 & 972 \\
\hline 12:00 PM & 965 & 972 & 945 & 947 \\
\hline 12:03 PM & 987 & 987 & 970 & 971 \\
\hline 12:06 PM & 988 & 987 & 970 & 970 \\
\hline 12:09 PM & 986 & 986 & 968 & 969 \\
\hline 12:12 PM & 988 & 986 & 971 & 971 \\
\hline 12:15 PM & 987 & 986 & 970 & 970 \\
\hline 3:00 PM & 982 & 982 & 968 & 969 \\
\hline 3:03 PM & 983 & 979 & 971 & 963 \\
\hline 3:06 PM & 982 & 982 & 970 & 969 \\
\hline 3:09 PM & 981 & 981 & 967 & 968 \\
\hline $3: 12$ PM & 960 & 964 & 940 & 940 \\
\hline $3: 15$ PM & 758 & 733 & 762 & 628 \\
\hline 6:00 PM & 765 & 785 & 716 & 720 \\
\hline 6:03 PM & 741 & 756 & 688 & 687 \\
\hline 6:06 PM & 720 & 738 & 664 & 667 \\
\hline 6:09 PM & 693 & 710 & 633 & 636 \\
\hline $6: 12 \mathrm{PM}$ & 662 & 671 & 599 & 594 \\
\hline $6: 15 \mathrm{PM}$ & 103 & 219 & 60 & 198 \\
\hline
\end{tabular}

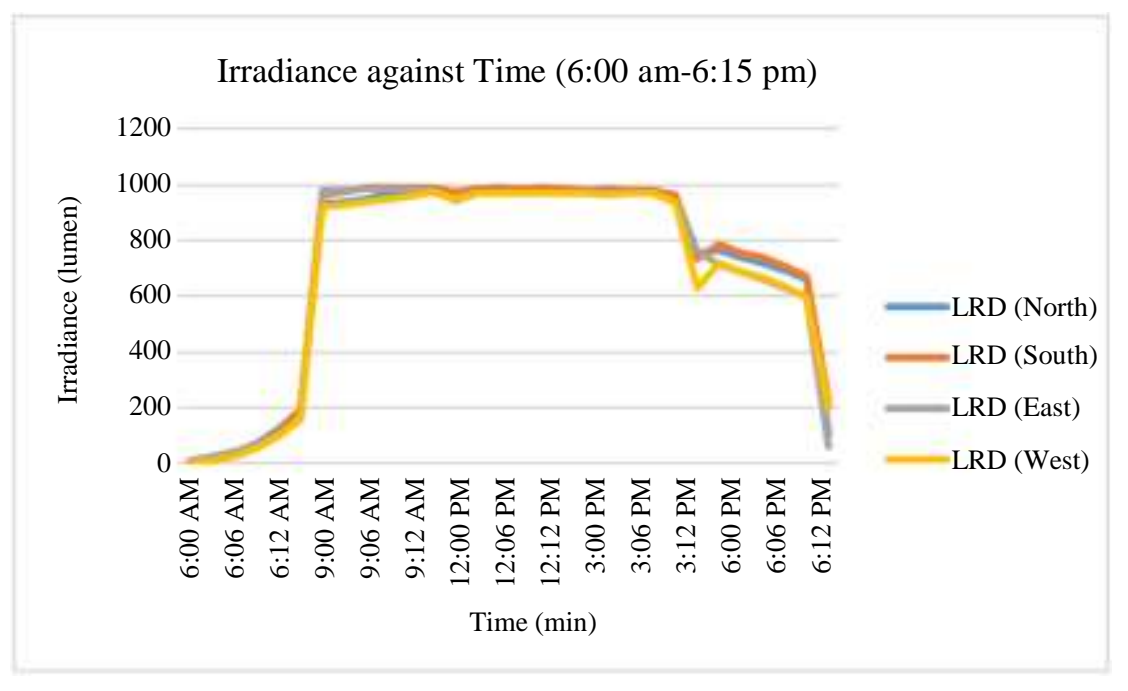

Fig. 5: Solar Irradiance against time (6:00 am-6:15 pm) 


\section{Conclusion}

The solar tracker prototype developed can be easily adopted and deployed anywhere looking at the simplicity of its design. It met its objective of tracking solar irradiance and accordingly re-orient the payload in real time to the point of maximum solar insolation. Testing and observation using the developed prototype as shown in Fig. 3 gave evidence to the fact that solar trackers can increase the efficiency of solar harvesters. The entire system was power by 5 volts which made it energy efficient and can be run at low cost.

\section{Author Contributions}

All authors equally contributed in this work.

\section{Ethics}

This article is original and contains unpublished material. The corresponding author confirms that all of the other authors have read and approved the manuscript and no ethical issues involved.

\section{References}

Hafez, A. Z., Yousef, A. M., \& Harag, N. M. (2018). Solar tracking systems: Technologies and trackers drive types-A review. Renewable and Sustainable Energy Reviews, 91, 754-782. https://doi.org/10.1016/j.rser.2018.03.094
Lee, J. F., \& Rahim, N. A. (2013, November). Performance comparison of dual-axis solar tracker vs static solar system in Malaysia. In 2013 IEEE Conference on Clean Energy and Technology (CEAT) (pp. 102-107). IEEE. https://doi.org/10.1109/CEAT.2013.6775608

Mareeswari, R., Tharani, S., Niveditha, G., \& Nithya, T. (2019). Solar tracking system a desideratum using LDR and microcontroller package. International Journal of Advanced Research (IJAR), 7(11), 254-259. https://doi.org/10.21474/IJAR01/10000

Thomas, T. A., \& Stephen E. S. (2014). Explorations: An introduction to Astronomy. https://www4.uwsp.edu/physastr/kmenning/Astr311 /Lect02.pdf

\section{Abbreviation and Units}

\begin{tabular}{lll}
\hline Abbreviation & Units & \\
\hline AVR & $\circ$ & Degree \\
LDR & $\Omega$ & Ohm
\end{tabular}

